\title{
A Modified Perchlorate Discharge Test for Detection of the Partial Defect of Iodide Organification in Thyroid
}

\author{
Keisuke TAKEUGHI, Yoshihiko HORIUGHI and Keimei MASHIMO \\ The Second Department of Internal Medicine, Hokkaido University. School of Medicine, \\ Sapporo, Japan. (Director ; Professor Keimei Mashimo, M.D.)
}

Perchlorate discharge tests were carried out in normal subjects who took an iodine restricted diet by the customary technique employed in this laboratory, wherein $1.0 \mathrm{gr}$. potassium perchlorate is given by mouth $3 \mathrm{hr}$ after an oral dose of $\mathrm{Na}^{131} \mathrm{I}$, and thyroidal ${ }^{131} \mathrm{I}$ uptake rate was studied 3 and $4 \mathrm{hr}\left(1 \mathrm{hr}\right.$ after $\mathrm{KClO}_{4}$ administration) after a ${ }^{131} \mathrm{I}$ dose, with the collimated scintillation counter. The ${ }^{131} \mathrm{I}$ discharge values were calculated by the following formula.

${ }^{131} \mathrm{I}$ discharge value $(\%)=\frac{3 \mathrm{hr} \text {, uptake rate }-4 \mathrm{hr} \text { uptake rate }}{3 \mathrm{hr} \text {-uptake rate }} \times 100$

1) Doses of $0.5 \mathrm{mg}$. of carrier ${ }^{127} \mathrm{I}$ and ${ }^{131} \mathrm{I}$ were given by mouth to 6 subjects, and ${ }^{131} \mathrm{I}$ uptake rates and ${ }^{131} \mathrm{I}$ discharge values were examined. The mean $3 \mathrm{hr}$ uptake rate was $4.35 \pm 1.35 \%$, and the mean ${ }^{131} \mathrm{I}$ discharge value after perchlorate administration was $-6.75 \pm 15.41 \%$. A negative discharge of ${ }^{131} \mathrm{I}$ from thyroids was shown.

2) In 5 subjects who received $2.0 \mathrm{mg}$. of carrier ${ }^{127} \mathrm{I}$ and ${ }^{131} \mathrm{I}$ tracer, the perchlorate discharge tests were also negative, the mean ${ }^{131} \mathrm{I}$ discharge value was $-7.58 \pm 4.30 \%$.

3) 5 subjects were pretreated with $10 \mathrm{mg}$. of mercaptoimidazol per day for 3 days. Thereafter, perchlorate discharge tests were carried out without carrier ${ }^{127} \mathrm{I}$ administration. The mean ${ }^{131} \mathrm{I}$ discharge value was $3.63 \pm 6.35 \%$ and ${ }^{131} \mathrm{I}$ discharge in the tests was negative.

4) Doses of $0.5 \mathrm{mg}$. of carrier ${ }^{127} \mathrm{I}$ and ${ }^{131} \mathrm{I}$ were given to 4 subjects who were pretreated with $10 \mathrm{mg}$. of mercaptoimidazol per day for 3 days, thyroidal ${ }^{131} \mathrm{I}$ uptake rate were examined on 3 and $4 \mathrm{hr}$ after ${ }^{127} \mathrm{I}$ and ${ }^{131} \mathrm{I}$ dose without perchlorate administration. The mean 3 and $4 \mathrm{hr}$ uptake rates were $3.70 \pm 0.49$ and $3.85 \pm 0.62 \%$, respectively.

5) In 6 subjects pretreated with mercaptoimidazol $(10 \mathrm{mg}$. for 3 days). Doses of $0.5 \mathrm{mg}$. of carrier ${ }^{127} \mathrm{I}$ were given by mouth with ${ }^{131} \mathrm{I}$, there was a positive discharge of ${ }^{131} \mathrm{I}$ from thyroids. The ${ }^{131} \mathrm{I}$ discharge value was $38.68 \pm 6.86 \%$.

In japanese persons, the daily excretion of iodide in urine generally amounted to 0.5 to $5.0 \mathrm{mg}$. and less than $0.5 \mathrm{mg}$. in subjects who were taking an iodine restricted diet. It did not seem that the administration of $0.5 \mathrm{mg}$. of carrier ${ }^{127} \mathrm{I}$ caused in normal subjects an acute inhibitory effect on organic binding of iodide in the thyroid. Perchlorate discharge tests carried out in subjects pretreated with a small dose of mercaptoimidazol for 3 days. The tests by customary methods were negative. But, a significant positive discharge of ${ }^{131} \mathrm{I}$ was observed when they were administrated with $0.5 \mathrm{mg}$. of carrier ${ }^{127} \mathrm{I}$ and ${ }^{131} \mathrm{I}$ tracer 
simultaneously. We suggested that a slight impaired organic binding caused by MMI treatment was not detected by the cutsomary methods, but was detected by a modified perchlorate test to which was added the condition of $0.5 \mathrm{mg} .{ }^{127} \mathrm{I}$ combined administration with ${ }^{131}$ I dose. However, we are unable to deny a possibility that doses of MMI and iodide acted sinergistically to produce an inhibition of thyroidal organic binding reactions when given together.

(See pp. 734 737) 


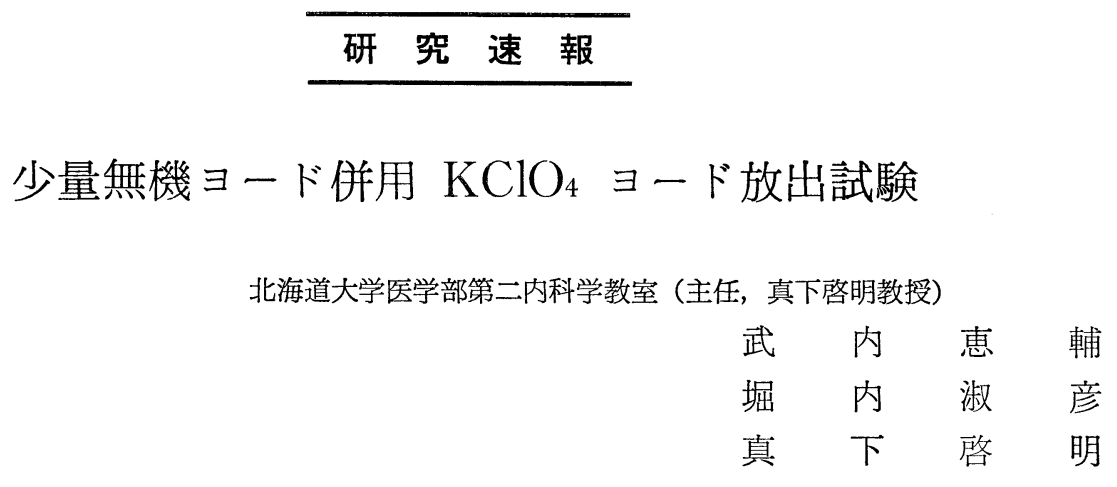

（昭和44年 4 月14日受付）

正常人に Methimazole $10 \mathrm{mg} 3$ 日間投与の前処置をして甲状腺に軽度の有機化障碍を作って $\mathrm{KClO}_{4}$ 試験を行なった。前処置によって生じた障碍はヨード制限食下での $\mathrm{KClO}_{4}$ 試験で ${ }^{131} \mathrm{I}$ 放出がみられ ず，無機ヨード $0.5 \mathrm{mg}$ を ${ }^{131} \mathrm{I}$ tracer と共に投与した $\mathrm{KGlO}_{4}$ 試験で放出がみられた。臨床的に，甲 状腺の軽度の有機化障碍の検出に有用であり，あるいはヨードに過敏に反応し抑制効果が生じる甲状腺 腫の検出に有用な手段として提唱する。

$$
\text { <緒 言 }>
$$

Stanbury ${ }^{1)}$ は家族性クレチンの症例に KSCN を投与し甲状腺からの ${ }^{131} \mathrm{I}$ の放出をみることにより先天 性の甲状腺内ョード有機化障碍が甲状腺腫の原因であることを示して以来，甲状腺ホルモン合成過程のうち

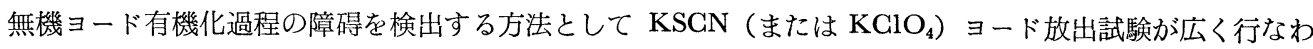
れている．我々は無機ヨード $0.5 \mathrm{mg}$ を $\mathrm{KI}$ 液として経口投与する条件で $\mathrm{KClO}_{4}$ 試験を行ない，有機化の より部分的な障碍を証明しようと試みた。

\section{〈対象亡方 法〉}

内分泌系，心，腎疾患のないものを甲状腺機能正常者としてえらび，ヨード制限食を 1 週間以上摂らせた 後, 実験を行なつた。

5 名は前処置として Methimazole 5mg. を朝夕 2 回ずつ 3 日間投与後 $\mathrm{KGlO}_{4}$ 試験を行なつた.

8 名は前処置なしに KI 液を用い無機ヨード $0.5 \mathrm{mg}$ を ${ }^{131} \mathrm{I}$ tracer と同時に経口投与して試験を行つた.

5 名には Methimazole 10mg. 3 日間投与の前処置を行ない，無機ヨード0.5mg を ${ }^{131} \mathrm{I}$ tracer と共に経 口投与した条件で $\mathrm{KClO}_{4}$ 試験を行なつた.

4 名は Methimazole 10mg. 3 日間投与の前処置を行ない，無機ヨード0.5mg ${ }^{131} \mathrm{I}$ tracer と共に投与 した際の $3 ， 4$ 時間摂取率を $\mathrm{KClO}_{4}$ の投与をせずに測定した.

6 名には前処置なしに無機ヨード $2.0 \mathrm{mg}$ を ${ }^{131} \mathrm{I}$ tracer と同時に経口投与して $\mathrm{KClO}_{4}$ 試験を行なつた.

$\mathrm{KGlO}_{4}$ 試験 $\mathrm{Na}^{131} \mathrm{I} 20 \sim 30 \mu \mathrm{G}$ を経口投与し 3 時間後甲状腺 ${ }^{131} \mathrm{I}$ 摂取率を測定し，直ちに $\mathrm{KGlO}_{4} 1.0 \mathrm{gr}$. を経口投与，その 1 時間後に再度 ${ }^{131} \mathrm{I}$ 摂取率を測定した。 ${ }^{131} \mathrm{I} の 3$ 時間摂取率（前值）と $\mathrm{KGlO}_{4}$ 投与後 1 時間值 (後值) から次の式で求められる值を無機 ${ }^{131} \mathrm{I}$ 放出率とした.

$$
\frac{\text { 前值一後值 }}{\text { 前值 }} \times 100=\text { 放出率 }(\%)
$$


測定装置は collimated scintillation counter 亿 A-filter を装置しクリスタルー甲状腺峡部皮膚面距離を $33 \mathrm{~cm}$ とした。 また body background は B-filter を装置し補正した。同一患者における ${ }^{131} \mathrm{I}$ 摂取率間の 測定誤差は土5\%以内であつた。

$$
\text { <結 果 }>
$$

Methimazole 前処置における $\mathrm{KClO}_{4}$ 試験 Methimazole 前処置したあとの $\mathrm{KClO}_{4}$ 試験をヨード制限食 下で行なつた時，甲状腺 3 時間 ${ }^{131} \mathrm{I}$ 摂取率は $4.80 \pm 3.35 \%, \mathrm{KClO}_{4}$ 投与 1 時間の後值は $4.72 \pm 3.49 \%$ ，放

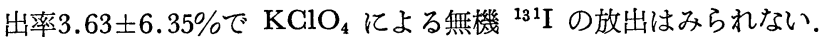

無機ヨード 0.5 mg. 併用 $\mathrm{KClO}_{4}$ 試験 Methimazole による前処置なしに $\mathrm{KClO}_{4}$ 試験を行なう際，無機 ヨード $0.5 \mathrm{mg}$ を ${ }^{131} \mathrm{I}$ tracer と同時に経口投与した条件で行なつた。 $\mathrm{KClO}_{4}$ 投与の前值は $4.35 \pm 1.35 \%$, 後值 $4.54 \pm 1.07 \%$ ，放出率は一 $-6.75 \pm 15.41 \%$ で，ての場合も $\mathrm{KClO}_{4}$ による無機 ${ }^{131} \mathrm{I}$ の放出はみられない.

Methimazole 前処置, 無機ヨード $\mathbf{0 . 5 m g}$ 併用時の甲状腺 ${ }^{131} \mathrm{I}$ 摂取率 Methimazole $10 \mathrm{mg} .3$ 日間投与 の前処置を行ない，無機ヨード $0.5 \mathrm{mg}$ を ${ }^{131} \mathrm{I}$ tracer と同時に経口投与せしめ，甲状腺 ${ }^{131} \mathrm{I}$ 摂取率を 3 時間 と 4 時間に測定し比較した。 3 時間值は $3.70 \pm 0.49 \% ， 4$ 時間値は $3.85 \pm 0.62 \%$ ，両值を結んだ勾配は下 降型を示していない.

Methimazole 前処置, 無機ヨード $\mathbf{0 . 5 m g}$ 併用 $\mathrm{KClO}_{4}$ 試験 Methimazole $10 \mathrm{mg} .3$ 日間投与の前処置を

Table 1. Results of perchlorate discharge tests in normal subjects 3 hour after oral administration of ${ }^{131} \mathrm{I}$ together with carrier ${ }^{127} \mathrm{I}$.

\begin{tabular}{|c|c|c|c|c|}
\hline $\begin{array}{l}\text { Number of } \\
\text { Subjects }\end{array}$ & Pretreatment & $\begin{array}{c}\begin{array}{l}\text { Dose of } \\
\text { Carrier }{ }^{127} \mathrm{I} \\
(\mathrm{mg})\end{array} \\
\end{array}$ & $\begin{array}{r}\text { Initial Uptake } \\
(\%)\end{array}$ & $\begin{array}{r}\text { Discharge } \\
(\%)\end{array}$ \\
\hline 5 & Mercazol 10mg 3 days & - & $4.80 \pm 3.35^{*}$ & $3.63 \pm 6.35$ \\
\hline 8 & - & 0.5 & $4.35 \pm 1.35$ & $-6.75 \pm 15.41$ \\
\hline 5 & Mercazol 10mg 3days & 0.5 & $4.82 \pm 0.66$ & $38.68 \pm 6.86$ \\
\hline 6 & - & 2.0 & $3.70 \pm 0.44$ & $-7.58 \pm 4.30$ \\
\hline
\end{tabular}

$*$ mean value $\pm \mathrm{SD}$

Table 2. Results of perchlorate tests in patients with chronic thyroiditis and simple goiter

\begin{tabular}{c|c|c|c|c}
\hline & $\begin{array}{l}\text { usual perchlorate test with no } \\
\text { carrier 127 }\end{array}$ & $\begin{array}{l}\text { modified perchlorate test with } \\
0.5 \mathrm{mg} \text { of carrier }{ }^{127} \text { I together } \\
\text { 131I dose }\end{array}$ \\
\cline { 2 - 5 } & $\begin{array}{c}\text { initial uptake } \\
(\%)\end{array}$ & $\begin{array}{c}\text { discharge value } \\
(\%)\end{array}$ & $\begin{array}{c}\text { initial uptake } \\
(\%)\end{array}$ & $\begin{array}{c}\text { discharge value } \\
(\%)\end{array}$ \\
\hline \hline Chronic thyroiditis & & & & \\
T.M. & 18.2 & 23.63 & 5.9 & 52.54 \\
K.M. & 5.7 & 0.00 & 5.5 & 20.00 \\
K.F. & 11.5 & 13.04 & 5.6 & 46.42 \\
Y.T. & 39.7 & 9.57 & 13.0 & 72.31 \\
H.T. & 43.5 & 3.45 & 31.7 & 75.08 \\
Simple goiter & & & 12.2 & 64.75 \\
T.Y. & 21.7 & -2.30 & 15.0 & 72.00 \\
S.S. & 26.4 & -3.03 & 10.8 & 37.96 \\
K.K. & 11.5 & 1.73 & & \\
\hline
\end{tabular}


行ない $\mathrm{KGlO}_{4}$ 試験を無機ヨード $0.5 \mathrm{mg}$ を carrier とし, ${ }^{131} \mathrm{I}$ と同時に投与する条件で行なつた時, 前值 すなわち 3 時間摂取率 $4.82 \pm 0.66 \%, \mathrm{KClO}_{4}$ 投与 1 時間の後值は $2.96 \pm 0.66 \%$, 放出率は $38.68 \pm 6.86 \%$ で ${ }^{131} \mathrm{I}$ の著明な放出が $\mathrm{KalO}_{4}$ 投与によりみられた。

無機ヨード 2.0mg 投与による $\mathrm{KCIO}_{4}$ 試験 前処置なしに, 無機ヨード $2.0 \mathrm{mg}{ }^{131} \mathrm{I}$ tracer と同時に経 口投与した時, 前值 $3.70 \pm 0.4 \%$, 後值 $43.73 \pm 0.47 \%$, 放出率-7.58 $\pm 4.30 \%$ で $\mathrm{KGlO}_{4}$ による無機 ${ }^{131} \mathrm{I}$ の放出はみられない.

症 例 慢性甲状腺炎患者 5 名と high uptake の単純性甲状腺腫患者 3 名に, ヨード制限食下での従来 の方法での $\mathrm{KClO}_{4}$ 試験の結果と無機ヨード $0.5 \mathrm{mg}$ を ${ }^{131} \mathrm{I}$ tracer と同時投与した際の $\mathrm{KGlO}_{4}$ 試験の成績 を Table 2 に示した. 患者 T.M. はョード制限下での $\mathrm{KClO}_{4}$ 試験で有意の ${ }^{131} \mathrm{I}$ の放出がみられ, ヨー ドの有機化障碍が内在していると考えられるが，ての症例に $0.5 \mathrm{mg}$ の無機ヨードを ${ }^{131} \mathrm{I}$ tracer と同時に投与 した条件での $\mathrm{KClO}_{4}$ 試験を行なつたところ, ${ }^{131} \mathrm{I}$ 放出率は 2 倍以上に増加を示した。 その他の症例ではヨ 一ド制限下での $\mathrm{KClO}_{4}$ 試験では全く ${ }^{131} \mathrm{I}$ の放出がないか，少量で有意とはいえない值を示すものが, $0.5 \mathrm{mg}$ の無機ヨードを投与した際には著明な ${ }^{131} \mathrm{I}$ の放出が $\mathrm{KGlO}_{4}$ 投与後みられた.

\section{<考按 $>$}

Morgans \& Trotter $^{2)}$ は橋本氏病患者に $\mathrm{KClO}_{4}$ 試験を行なつた時，一般の単純性甲状腺腫患者に比しヨ 一ドの放出が著明であることを示した. 我々は同様の方法で ${ }^{131} \mathrm{I}$ tracer を内服後 3 時間で阵状腺 ${ }^{131} \mathrm{I}$ 㩒取 率を計測， $\mathrm{KClO}_{4}$ 投与 1 時間後に再計測して ${ }^{131} \mathrm{I}$ の放出を検討したが，ヨード制限食下でのこの陽性率は 低い. しかし慢性甲状腺炎に限らず $\mathrm{KGlO}_{4}$ 試験が陰性である場合甲状腺のヨード有機化障碍は全く否定し てよいかどうか疑問がある。

日本人の日常食中のヨード摂取量はほぽ0.5〜 $5 \mathrm{mg}$ (北大病院常食) であり，海藻を厳重に制限した場合 のヨード捸取量は $0.5 \mathrm{mg}$ 以下（北大病院ヨード制限食約 $150 \mu \mathrm{g}$ ）となり正常人に $\mathrm{KGlO}_{4}$ 試験を行なう時, ヨード制限食で，また常食下においても無機 ${ }^{131} \mathrm{I}$ 放出はみられない. ヨード制限食下での血中無機ヨード 濃度は $7 \pm 1.8 \mu \mathrm{g} / \mathrm{l}$ ，乙れに $1 \mathrm{mg}$ 無機ヨードを投与したものを日常食とみると $14.5 \pm 3.1 \mu \mathrm{g} / 1$ の值をとる ${ }^{3)}$. ヨード制限食下に0.5mgの無機ヨードを経口投与した場合の血中無機ヨード濃度は，乙の值を上回わりうる が，それによる甲状腺無機ヨード摄取量は，正常日本人ではヨード有機化に急性抑制効果を示さないことが 結果から推定される.

Stewart \& Murray) は正常人に急性有機化障碍を生ぜしめる最少量は, 静注で $0.75 \mathrm{mg} ヨ$ ヨ゙している が，我々の実験とヨード投与の条件は相違しており，また我々の $2.0 \mathrm{mg}$ の無機ヨードを経口投与しての

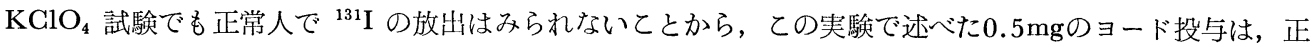
常人に甲状腺の有機化の急性抑制効果をひきおこす量とは言えない.

しかしながら，前処置として Methimazole を $10 \mathrm{mg} 3$ 日間経口投与した状態で正常人に $\mathrm{KGlO}_{4}$ 試験を 行なう時, 有意の ${ }^{131} \mathrm{I}$ 放出がみられたととから次の 2 つの推論がなされる.すなわち, 前処置に行なつた Methimazole 投与によつて軽度の有機化障碍が甲状腺に生じた. しかしての障碍は軽度のものであるため, ヨード制限下での $\mathrm{KClO}_{4}$ 試験では検出しえず carrier として投与した少量の無機 ヨードが甲状腺に摂取 された時, 甲状腺のヨード有機化処理能を越えた無機ヨードが $\mathrm{KClO}_{4}$ 投与により甲状腺から放出されたも のと考えられる． $0.5 \mathrm{mg}$ の無機ヨードを併用した時でも， $\mathrm{KClO}_{4}$ 投与を行なわない時は，甲状腺 ${ }^{131} \mathrm{I}$ 摂 取率は 3 時間と 4 時間とを比べても減少がみられず，有機化障碍の存在は検出しえない，第 2 の考え方は， 用いた無機ヨードと Methimazole は, 各々単独に投与した時, それが少量であるため有機化障碍は発生せ ず，両者を同時に用いた場合はこれらの相乗作用によつて $\mathrm{KClO}_{4}$ 投与後 ${ }^{131} \mathrm{I}$ 放出がみられるものと考元 られる ${ }^{5)}$.

慢性甲状腺炎の多くのものと，ある種の単純性甲状腺腫では，正常人に与えた Methimazole 前処置の結 果生じた障碍に相当する変化が甲状腺に内在していて, $0.5 \mathrm{mg}$ 無機ヨード投与の条件での $\mathrm{KClO}_{4}$ 試験の結 
果 ${ }^{131} \mathrm{I}$ の著明な放出がみられるものと考えられ, 甲状腺内ョード有機化能の軽度の障碍の存在する可能性, もしくは，無機ヨードによる有機化抑制効果に対する過敏性の存在を予測せしめ, 臨床的に有用である.

一方過去に我々が報告した北海道の海岸性甲状腺腫患者のヨード動態の検索のなかで, 日常の食餌条件, 摄取ヨードが大量である環境で $\mathrm{KClO}_{4}$ 試験は陽性の ${ }^{131} \mathrm{I}$ 放出を示し， ヨード制限食下でてれがみられな い現象をみているが吕，上述したような変化が甲状腺に内在しているものと推定され，甲状腺腫の原因につ ながるものとして注目している。

$$
\text { <結 語> }
$$

正常人に Methimazole 処置するととにより, ヨード制限時における $\mathrm{KClO}_{4}$ 試験で ${ }^{131} \mathrm{I}$ の放出がなく, $0.5 \mathrm{mg}$ の無機ヨードを同時投与した $\mathrm{KGlO}_{4}$ 試験により ${ }^{131} \mathrm{I}$ の著明な放出がみられた。 ての状態は甲状腺 飞作られた有機化障碍が軽度であるため，少量の無機ヨードを併用した $\mathrm{KClO}_{4}$ 試験によつてのみ検出しう るものであるか, もしくはヨード抑制効果に対する甲状腺の感受性を高めた結果によるものと推論した。

本研究費の一部は International Atomic Energy Agency からの Grant No. 481RB によつた。

\section{<参 考 文 献>}

1) STANBURY, J.B. and A.N. HEDGE : J. Clin. Endocrinol., $10: 1471$, (1950).

2) MORGANS, M.E. and W.R. TROTTER : Lancet, $1: 553$, (1957).

3) OHTAKI, S., S. MORIYA, H. SUZUKI and Y. HORIUGHI : J. Clin.Endocrinol., $27: 728$, (1967).

4) STEWART, R.D.H. and I.P.C. MURRAY : J. Glin. Endocrinol., $27: 500$, (1967).

5) PASTERNAK, D.P., E.L. SOCOLOW and S.H. INGBAR : Endocrinology, 84 : 769, (1969).

6) SUZUKI, H., T. HIGUGHI, K. SAWA, S. OHTAKI and Y. HORIUGHI : Acta Endocrinol., 50 : 161, (1965). 